\title{
Control of hypertension in out-patients. Experience of the Glasgow Blood Pressure Clinic
}

\author{
J. H. JoHNSTON \\ M.B., M.R.C.P., Major R.A.M.C. \\ J. C. Rodger \\ M.D., F.R.C.P.S.(Glas)
}

\author{
A. R. LORIMER \\ M.D., F.R.C.P. \\ W. K. ROBERTSON \\ B.Sc., Ph.D. \\ W. LAWRENCE \\ B.Sc.
}

\author{
R. FIFE \\ M.B., F.R.C.P.
}

Five hundred and sixty-two patients who had attended the Glasgow Blood Pressure Clinic regularly for 3 years between 1969 and 1978 were studied. The mean BPs for the group were $187 / 115 \mathrm{mmHg}$ initially, $157 / 100 \mathrm{mmHg}$ after 6 months, and $153 / 98 \mathrm{mmHg}$ after 3 years. Twenty-eight per cent had 'normal' systolic pressure and $22 \%$ 'normal' diastolic pressure at 3 years. Thirty-seven per cent with mild, $83 \%$ with moderate, and $89 \%$ with severe systolic pressure elevation had moved into less severe categories by 3 years, as had $30 \%$ with mild, $60 \%$ with moderate and $84 \%$ with severe diastolic elevation. Those patients with severe hypertension, who did not attain a less severe grade, had a statistically significant drop in pressure. Four per cent of all patients, however, had moved into a more severe grade of systolic pressure elevation and $6 \%$ into a more severe diastolic pressure grade at 3 years.

These results suggest that the hospital Hypertension Clinic can play a useful part in the lowering of BP in out-patients. It is clear, however, that 'normal' BP levels are not achieved in a significant proportion of patients.

\section{Introduction}

High blood pressure is an important risk factor for the development of cardiovascular disease (Lew, 1973; Kannel, 1974). The knowledge that reduction of BP in severe hypertension reduces complications implies long-term supervision of therapy for many patients. Surveys have shown, however, that a large proportion of those receiving antihypertensive therapy have poorly controlled BP levels (Schoenberger et al., 1972; Hawthorne, Greaves and Beevers, 1974; Berglund, Andersson and Wilhelmsen, 1976; Alderman and Ochs, 1977). It has even been suggested (Freis, 1977) that the hospital out-patient clinic is unsatisfactory for the long-term management of hypertensive patients.

This communication attempts to evaluate the effectiveness of out-patient BP control at the Glasgow Blood Pressure Clinic.

\section{Patients and methods}

The Glasgow Blood Pressure Clinic began in January 1969 when hypertension clinics in 4 hospitals in the city adopted a common record format with storage of data in a central computer (Glasgow Blood Pressure Clinic, 1972). Patients are referred by their general practitioners and by other hospital departments. Most have essential hypertension, but patients with secondary hypertension also attend and many have vascular disease. Fom the inception of the Clinic until May 1978 when this study was made, documents from 3500 patients had been entered into store.

The records were obtained of all those patients who were not receiving antihypertensive therapy at the first attendance and who were reviewed at one month, 6 months ( \pm 3 months), one year $(-3$ 
months +6 months), 2 years ( \pm 6 months) and 3 years ( \pm 6 months) after initial attendance.

The mean pre-treatment systolic and diastolic BPs were calculated for the group. When several readings were available for an individual patient the mean of the values was taken. Mean standing systolic and diastolic BPs were obtained at the appropriate review times. The numbers of patients with 'normal' systolic pressure (arbitrarily defined as $\leqslant 139 \mathrm{mmHg})$ or diastolic pressure $(\leqslant 89 \mathrm{mmHg})$ were obtained for the initial attendance and for the follow-up times. Patients were then classified arbitrarily as regards severity by the untreated systolic pressures in $\mathrm{mmHg}$ into 3 grades-mild $(140-179 \mathrm{mmHg})$, moderate $(180-199 \mathrm{mmHg}$, or severe $(\leqslant 200 \mathrm{mmHg}$ ); and again by the untreated diastolic BP into mild (90-99 $\mathrm{mmHg}$ ), moderate $(100-119 \mathrm{mmHg})$ and severe $(\geqslant 120 \mathrm{mmHg})$. These 6 groups were considered separately and the numbers in each having normal pressure and mild, moderate or severe elevation of pressure as already defined were found for the respective review dates. The mean BP values of those patients with initial severe elevation of BP who still had severe pressure elevation at 3 years were obtained. Student's $t$ test was used to assess the significance of changes in mean BP.

\section{Results}

Five hundred and sixty-two patients met the criteria for the Study.
Age and Sex

The mean age at initial acceptance was 48.7 years (s.d. $\pm 10 \cdot 6$, range 17-74). Two hundred and eighty-four $(50.5 \%)$ were male and $278(49.5 \%)$ female.

\section{Therapy}

All except $34(6 \%)$ received antihypertensive drugs (most of the exceptions had relatively mild hypertension and were participating as controls in a therapeutic trial).

\section{Mean BPs are given in Table 1}

The mean initial BP for the group was 186/ $115 \mathrm{mmHg}$ indicating that the group as a whole had relatively severe hypertension. After one month the systolic BP fell by $9.5 \%$ and the diastolic by $7.4 \%$. Between then and 6 months, there was a further drop of $7 \%$ in the systolic pressure and $5.9 \%$ in the diastolic. The levels were stable thereafter until at 3 years the systolic pressure had fallen by another $4.1 \%$ from the 6 months level and the diastolic by $2 \cdot 3 \%$.

\section{Numbers achieving 'Normal' pressures}

Table 2 gives the number of patients achieving 'normal' systolic BP at the various stages in their follow-up and Table 3 gives similar information of numbers of patients achieving a 'normal' diastolie pressure. There was a steady increase in the numbers

TABLE 1. Mean systolic and diastolic BPs in $\mathrm{mmHg}( \pm$ s.d.) at initial assessment and at follow-up in 562 patients

\begin{tabular}{llccccc}
\hline Systolic & $186 \cdot 6$ & $168 \cdot 8^{*}$ & 157 & $155 \cdot 9$ & $155 \cdot 5$ & $152 \cdot 9 * *$ \\
pressure & $(30 \cdot 2)$ & $(28 \cdot 6)$ & $(24 \cdot 9)$ & $(25 \cdot 0)$ & $(25 \cdot 6)$ & $(25 \cdot 4)$ \\
Diastolic & 115 & $106 \cdot 5 *$ & $100 \cdot 2$ & 100 & $99 \cdot 2$ & $99 \cdot 9 * *$ \\
pressure & $(15 \cdot 9)$ & $(14 \cdot 1)$ & $(12 \cdot 5)$ & $(13 \cdot 4)$ & $(13 \cdot 5)$ & $(14 \cdot 4)$ \\
Time & Initial & 1 month & 6 months & 1 year & 2 years & 3 years \\
\hline
\end{tabular}

*Difference from initial figure significant at $P<0.001$.

**Difference from 6 month figure significant at $P<0.005$.

TABLE 2. Numbers (\%) having normal systolic BP ( $\leqslant 139 \mathrm{mmHg})$ at initial assessment and at follow-up out of a total of 562 patients

\begin{tabular}{lcccccc}
\hline $\begin{array}{l}\text { Numbers } \\
(\%)\end{array}$ & 15 & 68 & 124 & 133 & 149 & 155 \\
Time & $(2 \cdot 7)$ & $(12 \cdot 1)$ & $(22 \cdot 1)$ & $(23 \cdot 7)$ & $(26 \cdot 5)$ & $(27 \cdot 6)$ \\
Initial & 1 month & 6 months & 1 year & 2 years & 3 years \\
\hline
\end{tabular}

TABLE 3. Numbers (\%) having normal diastolic BP $(\leqslant 89 \mathrm{mmHg})$ at initial assessment and at follow-up out of a total of 562 patients

\begin{tabular}{lcccccc}
\hline Numbers & 15 & 37 & 84 & 85 & 102 & 124 \\
$(\%)$ & $(2 \cdot 7)$ & $(6 \cdot 6)$ & $(15)$ & $(15 \cdot 1)$ & $(18 \cdot 1)$ & $(22 \cdot 1)$ \\
Time & Initial & 1 month & 6 months & 1 year & 2 years & 3 years \\
\hline
\end{tabular}



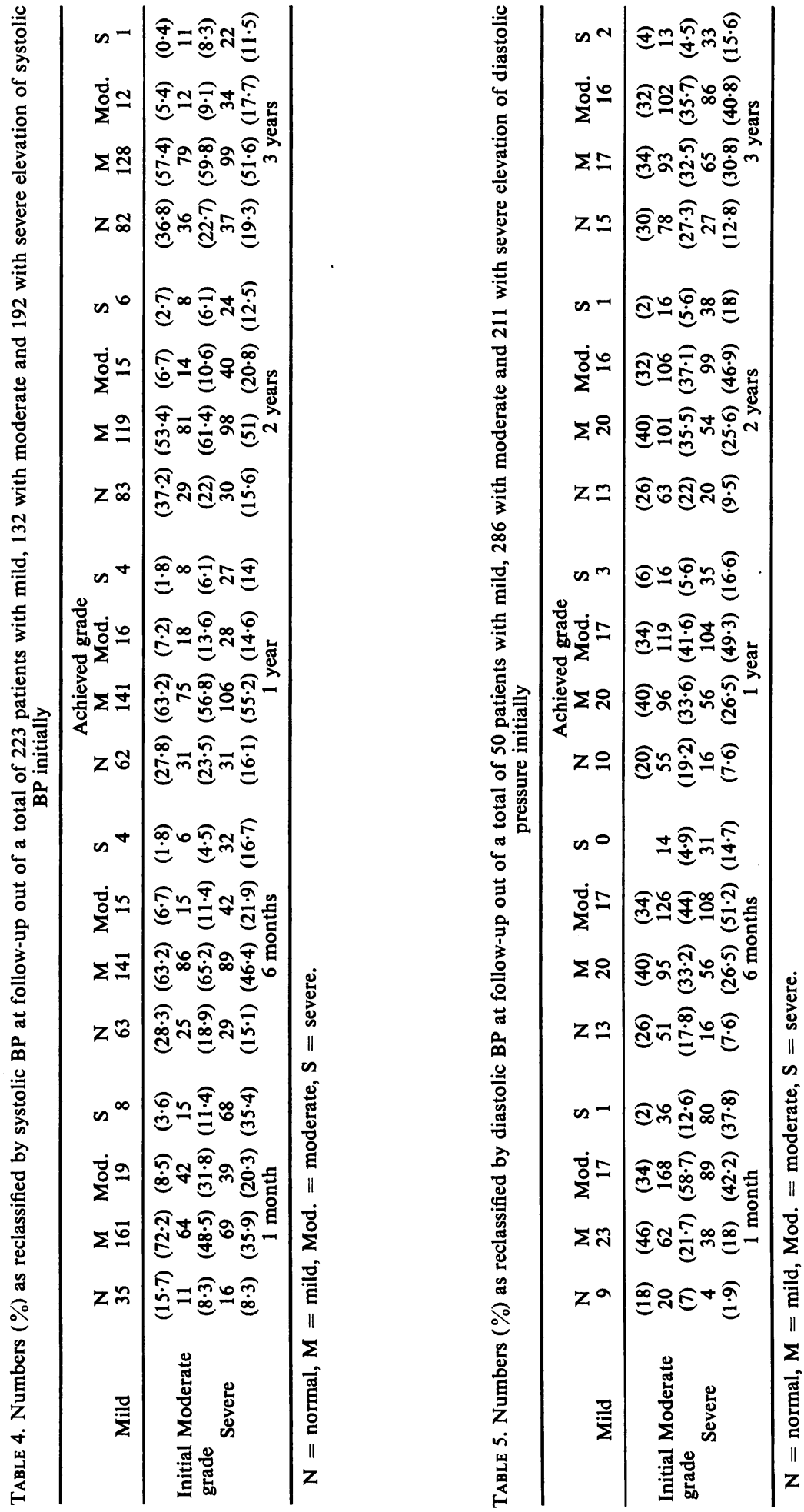
achieving normal pressures during the first 6 months of the follow-up but this increase was slower thereafter. Twenty-seven per cent. of the patients had achieved a 'normal' systolic BP at 3 years and $22 \%$ a 'normal' diastolic pressure. After the initial attendance more patients achieved 'normal' systolic values at each stage than achieved 'normal' diastolic values.

\section{Reduction in severity of hypertension}

The initial systolic BP was classed as mild in 223 patients $(39.6 \%)$, moderate in 132 patients $(23.5 \%)$, and severe in 192 patients $(34.2 \%)$. The initial elevation of diastolic pressure was mild in 50 patients $(8.9 \%)$, moderate in 286 patients $(50.9 \%)$, and severe in 211 patients $(37.5 \%)$.

Table 4 shows the comparison between the initial systolic BP elevation and that achieved at follow-up. Of those with mild elevation of systolic pressure initially, $36 \%$ were able to be re-classified as 'normal' after 3 years. However, $5.4 \%$ had moved up to moderate elevation and $0.4 \%$ (one patient) had moved to the severe category. After 3 years, therefore, about $57 \%$ remained in the mild systolic elevation category.

Those with initial moderate elevation of BP seemed to fare better in that after 3 years $22 \%$ were classified as 'normal' and $59 \%$ as mild. However, $9 \%$ remained in the moderate category and $8 \%$ had moved up to the more severe category.

Those initially regarded as having severe elevation of systolic BP seemed to do better still by this method of appraisal. After 3 years $19 \%$ were in the 'normal' category, $51 \%$ mild, $17 \%$ moderate, and only $11 \%$ remained in the severe category.

Table 5 shows the results of the follow-up on the severity grading for diastolic BP. The results were generally similar to the review of systolic pressures. In the group regarded initially as severe, however, $15 \%$ were finally classified at 3 years as 'normal', $31 \%$ as mild and $41 \%$ as moderate, in terms of their diastolic pressure. This left only $15 \%$ of the patients with severely elevated diastolic pressure who had not achieved some improvement in their category.

\section{Patients with persistently severe hypertension}

The 22 patients who had persistently severe elevation of systolic pressure after 3 years of followup had an initial mean systolic pressure for the group of $230 \cdot 9 \pm$ s.d. $26 \cdot 2 \mathrm{mmHg}$, and at 3 years $210 \cdot 1 \pm$ s.d.12.9 mmHg. This represents a mean fall in systolic pressure of $20.8 \mathrm{mmHg}(P<0.005)$.

The 33 patients with persistently severe diastolic pressure elevation after a 3-year follow-up had a mean diastolic pressure initially of $134 \cdot 8 \pm$ s.d.14.6
$\mathrm{mmHg}$ and finally at 3 years of $128 \pm$ s.d.10.5 mmHg which is a mean fall of $6.8 \mathrm{mmHg}(P<0.025)$.

\section{Discussion}

It has been shown, at least in males, that lowering the BP in those with moderate or severe hypertension is accompanied by a reduced incidence of stroke, cardiac failure, uraemia and retinal damage (Veterans Administration Co-operative Study Group, 1967, 1970). The need for treatment in such patients and in those already suffering from vascular complications seems clear. Although full information is not available it is possible that benefits will also occur in treating females with hypertension (Hamilton, Thompson and Wisniewski, 1964) and those with milder hypertension. These groups are also at risk (Kannel 1974) and it has been recommended that they be treated (Committee on Hypertension, 1973; Ayers et al., 1973; Report, 1977) The aim of treatment is usually accepted as a reduction to as near normal a BP level as possible, although this may be difficult to achieve. However, even incomplete control of the BP has been shown to reduce the incidence of vascular complications (Dorph et al., 1970; Taguchi and Freis, 1974) and it has been suggested (Ingelfinger and Goldman, 1977) that there is little evidence to show that lowering BP to normal confers any additionat advantage.

Although the merits of controlling high BP are recognized, surveys (Schoenberger et al., 1972; Hawthorne et al., 1974; Berglund et al., 1976) have suggested that adequate BP control is difficult to achieve in practice, especially where large numbers of patients are concerned. Beevers et al., (1973) $\stackrel{\varnothing}{\varnothing}$ have reported $60 \%$ of patients achieving a diastolic $\overrightarrow{0}$ BP of $100 \mathrm{mmHg}$ or less when followed over a 3 2-year period. In $40 \%$, however, this standard $\vec{P}$ could not be achieved and in $10 \%$ no form of satisfactory control was obtained.

The patients reported here represent those attending the clinic for whom full information was available as regards pre-treatment levels of $\mathrm{BP}$ and in whom the required follow-up visits up to 3 O years had been achieved. We have thus excluded a

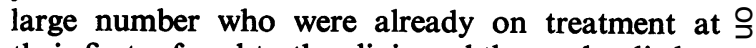
their first referral to the clinic and those who died or $D$ defaulted within the required 3 -year period. It should also be understood that the patients were o not all attending simultaneously and that the information was collected from patients attending 0 over the time span 1969 to 1978 . A wide range of $\tilde{\omega}$ antihypertensive regimes was employed.

The results indicate that in many patients a reduction in both systolic and diastolic BP is present within one month of attendance and that $\stackrel{\leftrightarrow}{\rightarrow}$ further falls take place over the next 12 months. 
By one year the average fall in systolic pressure was approximately $30 \mathrm{mmHg}$ and in diastolic pressure was $15 \mathrm{mmHg}$. These mean reductions were maintained over the next 2 years.

The incidence of cardiovascular complications is related to the height of the BP (Kannel, 1974) and in this context it is important to note that the more severe the initial hypertension the more likely were the patients to have achieved a lower grade of BP at follow-up. Greater falls in absolute terms were achieved in systolic pressure than in diastolic pressure. This is acceptable, however, since the systolic pressure appears to be as important an indicator of hypertensive complications (Kannel, Gordon and Schwartz 1971).

The results, however, give no grounds for complacency. At the end of 3 years, 34 patients were still regarded as having severe elevation of systolic pressure and 48 patients severe elevation of diastolic pressure. These patients included some who had increased their severity of hypertension during the phase of attempted therapy.

This study does not seek to assess the value of lowering BP in the prevention of complications. It does, however, show some evidence that specialist clinics are capable of making a contribution to the control of BP in large numbers of patients over a period of years.

\section{References}

Alderman, M.H. \& OCHS, O.S. (1977) Treatment of hypertension at the university medical clinic. Archives of Internal Medicine, 137, 1707.

Ayers, C.R., Slaughter, A.R., Smallwood, M.D., TAYLOR, F.E. \& WeITZMAN, R.E. (1973) Standards for quality care of hypertensive patients in office and hospital practice. American Journal of Cardiology, 32, 533.

Beevers, D.G., Fairman, M.J., Hamilton, M. \& Harpur, J.E. (1973) The influence of antihypertensive treatment over the incidence of cerebral vascular disease. Postgraduate Medical Journal, 49, 905.

Berglund, G., Andersson, O. \& Wilhelmsen, L. (1976) Prevalence of primary and secondary hypertension: studies in a random population sample. British Medical Journal, 2, 554.
COMmitTeE ON HyPERTENSION (1973) Drug treatment of ambulatory patients with hypertension. Journal of the American Medical Association, 225, 1647.

Dorph, S., Leth, A., Degnbol, B. \& From, A. (1970) Visceral changes in severe hypertension and their response to drug treatment. Acta medica scandinavica, 187, 411.

FreIS, E.D. (1977) The mismanagement of hypertension. Archives of Internal Medicine, 137, 1669.

Glasgow Blood Pressure Clinic (1972) Journal of the Royal College of Physicians of London, 7, 87.

Hamilton, M., Thompson, E.W. \& W ISNiEWsKi, T.K.M (1964) The role of blood pressure control in preventing complications of hypertension. Lancet, $\mathbf{i}, 235$.

Hawthorne, V.M., Greaves, D.A. \& BeEvers, D.G. (1974) Blood pressure in a Scottish town. British Medical Journal, 3,600 .

INGELFINGER, J.A. \& GoldMAN, P. (1977) Therapy for hypertension. How much of what drug for whom? Journal of the American Medical Association, 238, 1369.

KANNEL, W.B. (1974) Role of blood pressure in cardiovascular morbidity and mortality. Progress in Cardiovascular Diseases, 17, 5.

Kannel, W.B., Gordon, T. \& Schwartz, M.J. (1971) Systolic versus diastolic blood pressure and the risk of coronary heart disease. American Journal of Cardiology, 27, 335.

LEw, E.A. (1973) High blood pressure, other risk factors and longevity: the insurance viewpoint. American Journal of Medicine, 55, 281.

REPORT OF THE JOINT NATIONAL COMMITTEE ON DETECTION, EVALUATION AND TREATMENT OF HIGH BLOOD PRESSURE (1977) A co-operative study. Journal of the American Medical Association, 237, 255.

Schoenberger, J.A., Stamler, J., Shekelle, R.B. \& SHEKELLE, S. (1972) Current status of hypertension control in an industrial population. Journal of the American Medical Association, 222, 559.

TAGUCHI, J. \& FREIS, E.D. (1974) Partial reduction of blood pressure and prevention of complications in hypertension. New England Journal of Medicine, 291, 329.

Veterans Administration Co-OPERATIVE Study Group on ANTIHYPERTENSIVE AGENTS (1967) Effects of treatment on morbidity in hypertension. Results in patients with diastolic blood pressures averaging 115 through $129 \mathrm{mmHg}$. Journal of the American Medical Association, 202, 116.

Veterans Administration Co-Operative Study Group on ANTIHYPERTENSIVE AGENTS (1970) Effects of treatment on morbidity in hypertension II. Results in patients with diastolic blood pressures averaging 90 through $114 \mathrm{mmHg}$. Journal of the American Medical Association, 213, 1143. 